\title{
Chronic hyperkalemia in non-dialysis CKD: controversial issues in nephrology practice
}

\author{
Luca De Nicola ${ }^{1} \cdot$ Luca Di Lullo $^{2} \cdot$ Ernesto Paoletti $^{3} \cdot$ Adamasco Cupisti $^{4} \cdot$ Stefano Bianchi $^{5}$
}

Received: 5 March 2018 / Accepted: 23 May 2018 / Published online: 7 June 2018

(c) The Author(s) 2018

\begin{abstract}
Chronic hyperkalemia is a major complication of chronic kidney disease (CKD) that occurs frequently, heralds poor prognosis, and necessitates careful management by the nephrologist. Current strategies aimed at prevention and treatment of hyperkalemia are still suboptimal, as evidenced by the relatively high prevalence of hyperkalemia in patients under stable nephrology care, and even in the ideal setting of randomized trials where best treatment and monitoring are mandatory. The aim of this review was to identify and discuss a range of unresolved issues related to the management of chronic hyperkalemia in non-dialysis CKD. The following topics of clinical interest were addressed: diagnosis, relationship with main comorbidities of CKD, therapy with inhibitors of the renin-angiotensin-aldosterone system, efficacy of current dietary and pharmacological treatment, and the potential role of the new generation of potassium binders. Opinion-based answers are provided for each of these controversial issues.
\end{abstract}

Keywords Hyperkalemia $\cdot$ Chronic kidney disease $\cdot$ Anti-RAAS $\cdot$ Potassium binder

\section{Introduction}

In 2007, the National Kidney Foundation launched the message that non-dialysis chronic kidney disease (CKD) is "common, harmful, and treatable" [1]. The purpose of this message was to raise awareness of CKD in order to improve diagnosis and treatment of this high-risk condition. Since then, the population of CKD patients referred to renal clinics has grown considerably, in recognition of the value of conservative treatment of CKD, even in advanced stages of the disease [2]. To paraphrase the afore-mentioned message, it is possible to state to a similar extent that hyperkalemia is

Luca De Nicola

luca.denicola@unicampania.it

1 Division of Nephrology, University of Campania, Piazza L. Miraglia, 1, 80138 Naples, Italy

2 Nephrology and Dialysis Unit, Parodi-Delfino Hospital, Colleferro, Rome, Italy

3 Nephrology, Dialysis and Transplantation, University of Genoa and Policlinico San Martino, Genoa, Italy

4 Department of Clinical and Experimental Medicine, University of Pisa, Pisa, Italy

5 Nephrology Unit, Azienda USL Toscana Nord Ovest, Leghorn, Italy a major complication of CKD, because it is frequent, associated with poor prognosis and potentially controlled by adequate therapy.

The prevalence of hyperkalemia reported in the most recent observational studies ranges from 1 to $50 \%$, and is mainly dependent on the threshold level of serum potassium (sK) used for diagnosis (Table 1) [3-12]. Moreover, prevalence strictly correlates with residual renal function; indeed, the kidney is the main regulator of potassium homeostasis, and impaired renal function is the essential prerequisite for the development and maintenance of chronic hyperkalemia [13]. Additional key modifiers of the hyperkalemia rate are comorbidities frequently encountered in the CKD population, namely diabetes and heart failure (HF), and use of the first-line agents for treatment of CKD, namely renin-angiotensin-aldosterone system antagonists (anti-RAAS), particularly if used in combination [13].

The relatively large prevalence of hyperkalemia in patients under stable nephrology care, and even in the ideal setting of randomized trials where best treatment and monitoring are mandatory, indicates that current strategies aimed at prevention and treatment of hyperkalemia are suboptimal.

The therapeutic issue becomes even more critical when considering the prognostic value of high sK levels. Indeed, the excess risk of mortality already becomes evident for even 
Table 1 Main observational studies published in the last 5 years on prevalence of hyperkalemia by eGFR

\begin{tabular}{|c|c|c|c|c|c|}
\hline Study [Ref.] & Setting & Sample size & $\begin{array}{l}\mathrm{eGFR} \mathrm{ml} / \\
\mathrm{min} / 1.73 \mathrm{~m}^{2}\end{array}$ & $\begin{array}{l}\text { Hyperkalemia preva- } \\
\text { lence, \% (definition) }\end{array}$ & Survival by sK level \\
\hline Hayes [3] & Renal clinic & 1227 & 37.0 & $7.7(s K>5.3)$ & $\downarrow$ for $\mathrm{sK}>5.5$ \\
\hline Drawz [4] & Veterans hospital & 13,874 & 46.5 & $2.5(s K \geq 5.5)$ & Not available \\
\hline Sarafidis [5] & Low-GFR clinic & 238 & 14.5 & $\begin{array}{l}54.2(s K>5.0) \\
31.5(s K \geq 5.5) \\
8.4(s K \geq 6.0)\end{array}$ & Not available \\
\hline Nakhoul [6] & CKD registry at Cleveland clinic & 36,359 & 47.0 & $\begin{array}{l}11.0(s K>5.0) \\
3.3(s K>5.5)\end{array}$ & $\downarrow$ for $\mathrm{sK}>5.0$ \\
\hline Luo [7] & Health care system & 55,266 & $<60$ & $\begin{array}{l}14.9(s K 5.0-5.4) \\
3.9(s K 5.5-5.9) \\
1.1(s K \geq 6.0)\end{array}$ & $\downarrow$ for $\mathrm{sK}>5.0$ \\
\hline Chang [8] & Health care system & 155,695 & $<60$ & $\begin{array}{l}5.3,19.0,9.4 \text { for }<2, \\
2 \text { to }<4, \geq 4 \mathrm{sK} \\
\text { test/year } \\
(s K>5.0)\end{array}$ & Not available \\
\hline Hughes [9] & General population & 9651 & 80.0 & $2.8(s K \geq 5.0)$ & $\downarrow$ for $\mathrm{sK} \geq 5.0$ \\
\hline Betts [10] & Medicare 2014 & 120,933 & $<60$ & $\begin{array}{l}9.4 \text { in CKD } 3 \\
19.5 \text { in CKD } 4 \\
18.5 \text { in CKD } 5 \\
52.8 \text { in dialysis } \\
(s K>5.0)\end{array}$ & Not available \\
\hline Núñez [11] & Heart failure & 2164 & 62.0 & $5.6(s K>5.0)$ & $\downarrow$ for $\mathrm{sK}>5.0$ \\
\hline Collins [12] & US integrated health delivery networks & 911,698 & $\begin{array}{l}\text { with and } \\
\text { w/o CKD } \\
(e G F R<60)\end{array}$ & $\begin{array}{l}8.3 \text { in } \mathrm{DM} \\
9.1 \text { in } \mathrm{HF} \\
11.5 \text { in } \mathrm{CKD} \\
13.1 \text { in combined } \\
(s K \geq 5.0)\end{array}$ & $\downarrow$ for $\mathrm{sK} \geq 5.0$ \\
\hline
\end{tabular}

$C K D$ chronic kidney disease, $e G F R$ estimated glomerular filtration rate, $s K$ serum potassium

minor degrees of hyperkalemia (Table 1), suggesting that $\mathrm{sK} \geq 5.0 \mathrm{mEq} / \mathrm{l}$ should receive the attention of nephrologists, because it likely poses future risk of further increases in sK to levels triggering fatal arrhythmias. Furthermore, it is possible that hyperkalemia may play an indirect role in the progression of CKD to dialysis by dictating the withdrawal of nephroprotective anti-RAAS agents [8]. Finally, hyperkalemia represents a main driver for dialysis initiation. In this regard, a recent survey among European nephrologists revealed that the clinical picture plays the decisive role, with hyperkalemia refractory to medical therapy eliciting preference for an immediate start of dialysis by $100 \%$ of nephrologists participating in the survey [14]. These results are coherent with contemporary guidelines that, while not identifying a specific estimated glomerular filtration rate (eGFR) level to start dialysis in stage 5, recommend it when complications become uncontrolled by conservative therapy [15].

Therefore, on the understanding that hyperkalemia is a main refractory complication of CKD, and that the presence of hyperkalemia per se markedly increases the economic expenditure for CKD due to more frequent and costly hospitalizations [16], we here address some major controversial issues in the clinical management of hyperkalemia and provide opinion-based answers.

\section{Number of blood samples needed to diagnose hyperkalemia in CKD}

No consensus exists on how many tests showing an increase in sK are needed to identify a clinically meaningful hyperkalemia. Current Kidney Disease Improving Global Outcomes (KDIGO) guidelines for the evaluation and management of CKD only suggest sK measurement within 1 week of starting anti-RAAS, or uptitrating dose, in subjects with reduced renal function [15]. Similarly, NICE guidelines [17] recommend sK testing in CKD patients administered antiRAAS before starting therapy and between 1 and 2 weeks thereafter and after each dose increase. Independently from anti-RAAS prescription, most observational studies have evaluated the prevalence of chronic hyperkalemia on the basis of a single sampling [6, 18, 19], whereas recent randomized controlled trials (RCTs) performed sK laboratory tests at least twice in order to identify subjects that could be enrolled for active treatment of hyperkalemia [20-22]. 
A recent study including CKD patients showed that detection of hyperkalemia increased as the number of sK tests increased [8]. In particular, in patients with eGFR ranging from 30 to $44 \mathrm{ml} / \mathrm{min} / 1.73 \mathrm{~m}^{2}$ and more than 4 laboratory tests/year available over a 3-year observation period, $\mathrm{sK}>5 \mathrm{mEq} / \mathrm{l}$ was found in $54 \%$ while $22 \%$ had $\mathrm{sK}>5.5 \mathrm{mEq} / \mathrm{l}$. Furthermore, the prevalence of hyperkalemia significantly increased with lower eGFR and the use of anti-RAAS. Of note, in the Renal Research Institute CKD Study cohort [23], an average of six sK values was obtained during a 2.6-year follow-up period in CKD patients in order to better identify subjects with hyperkalemia $(\mathrm{sK} \geq 5.5 \mathrm{mEq} / \mathrm{l})$.

Therefore, although single sK testing can identify patients at risk for chronic hyperkalemia, especially those with more advanced CKD and those administered anti-RAAS, testing at least two times per year seems to be a wise approach to properly identify chronic hyperkalemia. Assessment of sK in CKD patients becomes essential before starting antiRAAS therapy, 1-2 weeks thereafter, and at each uptitration of dose.

\section{Electrocardiogram for the stratification of hyperkalemia severity}

Chronic hyperkalemia is easily diagnosed by common laboratory tests, paying attention to exclude pseudohyperkalemia (Table 2) [24]. Bradycardia is an early sign of acute severe hyperkalemia that requires increased awareness, especially in the dialysis setting [25]. In chronic hyperkalemia, where bradycardia is uncommon because of adaptive mechanisms, electrocardiogram (ECG) monitoring allows to gain clinical insight into the severity of abnormalities related to sKdependent changes in cardiac rhythm (Fig. 1).

The progressive changes of hyperkalemia are classically listed as follows:

- ST-segment depression

- widening of the PR interval

- widening of the QRS interval

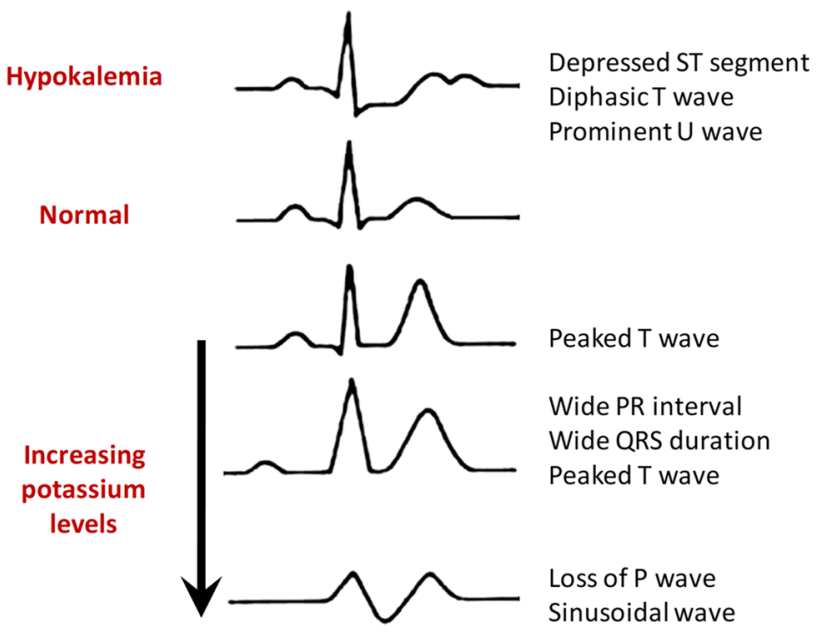

Fig. 1 Changes in electrocardiogram following progressive increases in potassium levels

- loss of the P-wave

- a sine-wave pattern - an ominous development and a harbinger of impending ventricular

- fibrillation and asystole [26].

However, sK levels often poorly correlate with cardiac manifestations. In a retrospective review, only 16 of 90 cases met criteria for ECG changes reflecting hyperkalemia (defined as new peaked and symmetric $\mathrm{T}$ waves that resolved on follow-up) [27]. In 13 of these cases, the ECG was interpreted as showing no T-wave changes even when read by a cardiologist. In addition, criteria for hyperkalemia were only noted in 1 of 14 patients who manifested arrhythmias or cardiac arrest attributed to increased sK concentration. Therefore, ECG can only be used as a support to stratify risk in patients with severe hyperkalemia, as previously suggested [28]. Indeed, although ECG is considered a main diagnostic tool for hyperkalemia diagnosis, this is true in only $40-50 \%$ of chronic hyperkalemic patients.

Table 2 Determinants of pseudohyperkalemia

\begin{tabular}{ll}
\hline Cause & Explanation \\
\hline Mechanical factors & $\begin{array}{c}\text { Tourniquet applied for prolonged periods, fist clenching, traumatic venipuncture or probing, vigorous mix- } \\
\text { ing or excessive centrifugal force of specimens } \\
\text { Ethanol containing antiseptics }\end{array}$ \\
$\begin{array}{l}\text { Chemical factors } \\
\text { Temperature }\end{array}$ & Specimens exposed to low $\left(2-8{ }^{\circ} \mathrm{C}\right)$ or above room temperature can result in potassium leakage \\
Time & Delayed processing can result in potassium leakage \\
Patient factors/diseases & Fear of venipuncture/crying and associated with hyperventilation (even for a few minutes) is associated \\
& with acute respiratory alkalosis and significant hyperkalemia. Thrombocytosis and chronic lymphocytic \\
leukemia can result in increased potassium levels & False plasma reference ranges or mislabelling, contaminants such as potassium containing intravenous fluids \\
Miscellaneous &
\end{tabular}




\section{Major risk factors for newly diagnosed hyperkalemia in CKD}

Among CKD-related hyperkalemia risk factors, HF is widely represented as it is frequently associated with low GFR [29]. Furthermore, patients with HF and CKD are extensively treated with anti-RAAS, and in particular with mineralocorticoid receptor antagonists (MRAs), that are major contributors to hyperkalemia onset [30]. Notably, in HF, hyperkalemia can also be related to reduced distal sodium delivery and GFR worsening, comorbidities other than CKD (diabetes mellitus, Addison's disease, hypoaldosteronism), as well as nonsteroidal anti-inflammatory drugs, and angiotensin receptor neprilisin inhibitors (ARNIs) [31].

In the PARADIGM-HF trial, approximately $15 \%$ of patients developed hyperkalemia in both treatment arms (ARNI and enalapril) [32]. Similar findings were observed in the RALES trial where a higher risk of mortality was observed with sK>5.5 mmol/l [33]. Finally, in the ADHERE study, more than $60 \%$ of patients presented with kidney disease, and up to $20 \%$ developed hyperkalemia [7, 34].

The incidence of hyperkalemia is also higher in diabetic patients [31]. Redistribution of potassium from the intracellular to the extracellular compartment can induce hyperkalemia with no net total body $\mathrm{K}^{+}$increase, as occurs in acidosis (for each 0.1 fall in $\mathrm{pH}$, $\mathrm{sK}$ increases by approximately $0.4 \mathrm{mmol} / \mathrm{l})$, insulin deficiency, hypertonicity, cell lysis (rhabdomyolysis), and drugs (e.g. beta blockers). The most common causal factor of chronic hyperkalemia in diabetics is the reduced tubular secretion of $\mathrm{K}^{+}$due to the hyporeninemic hypoaldosteronism syndrome [35]. Interestingly, the new antidiabetic drugs (e.g. sodium-glucose co-transporter-2 inhibitors) may actually protect patients from hyperkalemia due to the osmotic diuresis [35].

Therefore, CKD patients with $\mathrm{HF}$ and/or diabetes are at high risk of developing chronic hyperkalemia. In these patients, chronic hyperkalemia is often related to concomitant treatments (i.e. anti-RAAS, nonsteroidal anti-inflammatory drugs and ARNI) over and above the frequent concurrent GFR impairment.

\section{Nutritional management in CKD patients at risk of hyperkalemia}

In CKD patients, dietary interventions are prescribed in order to delay the start of dialysis [36], both in proteinuric and in non-proteinuric kidney disease [37, 38]. Diets are generally based on control/reduction of the intake of sodium, phosphate and proteins while providing an adequate supply of essential amino acids. A major point is that energy intake must cover the energy requirement
(30-35 Kcal/kg/day) to allow metabolic adaptation in the course of protein-restricted regimens, thus preventing negative nitrogen balance and protein-energy wasting. Diets rich in plant-based foods, as vegan or vegetarian regimes [39], provide additional favorable effects related to high amounts of alkali and fibers [40]. Lower net acid load and favorable effects on intestinal motility and microbiota are expected, but the resulting high potassium load is of concern.

Therefore, when protein restriction is needed in a CKD patient, an animal-based low-protein diet (LPD) could be favored over vegetarian-based LPDs [39].

However, the prevention or correction of metabolic acidosis as well as constipation may well counteract the hyperkalemia-inducing effects of high potassium intake. This may explain why an increase in sK or overt hyperkalemia in CKD patients is a rare finding in patients on vegetarian diets, with or without low protein content [41-44].

In patients with non-dialysis dependent CKD stages 1-5, the National Kidney Foundation suggests an unrestricted potassium intake (90-120 mmol/day) as for the recommended daily allowance in the general population unless hyperkalemia occurs [45]. Potassium intake should be limited to 2.7-3.1 g/day in hemodialysis patients and to 3-4 g/day in peritoneal dialysis patients; in either case, adjustment based on sK level is necessary. A recent comprehensive review has suggested an intake of $4.7 \mathrm{~g} / \mathrm{day}$ in the early stages of CKD without risk of hyperkalemia, while dietary potassium restriction down to 2-3 g/day (approximately 51-77 mmol/day) is recommended in CKD patients with $\mathrm{sK}>5.3 \mathrm{mEq} / 1$ [46].

Correct dietary counseling and intervention are therefore crucial in CKD patients in order to obtain clinical and metabolic beneficial effects together with good nutritional status while limiting dietary potassium load in the cases of chronic or recurrent hyperkalemia.

Careful recall of potassium intake may focus the dietary intervention and prevent excessive potassium load, leading to a reduction in $\mathrm{sK}$. Unfortunately, education for a dietary approach to limiting potassium-rich foods is uncommon during clinician visits. Studies on the effectiveness of potassium dietary management in patients with advanced CKD are needed because up to now, the efficacy of dietary counseling in the prevention or treatment of hyperkalemia remains to be demonstrated [47].

In summary, safe nutritional intakes in CKD patients at risk of hyperkalemia include: protein intake of $\leq 0.8 \mathrm{~g} /$ $\mathrm{kg} / \mathrm{day}$; salt intake of 5-6 g/day; phosphate intake of $\leq 700 \mathrm{mg} /$ day; energy intake of 30-35 Kcal/kg/day; potassium intake of 2-3 g/day and alkali and fiber intake of 25-30 g/day. 


\section{Control of potassium load while maintaining the benefit of a high-potassium diet}

A dietary potassium intake that surpasses output, i.e. a positive external potassium balance, plays a central role in the pathogenesis of chronic hyperkalemia [48]. Net intestinal absorption of dietary potassium is approximately $90 \%$. It is absorbed mostly in the duodenum and jejunum, and fecal excretion is constant at about $10 \mathrm{mmol} / \mathrm{day}$, with a maximum level of $15-20 \mathrm{mmol} / \mathrm{day}$.

Potassium concentration in the feces is very high (83-95 mmol/l) and the capacity of the colon/rectum to secrete potassium seems to be increased at very low levels of residual kidney function [49]. Slow fecal transit time along the intestinal tract favors potassium absorption, whereas faster intestinal transit time reduces potassium absorption [50]. This has led to the hypothesis that constipation, more than potassium dietary load, acts as the main determinant of hyperkalemia in end-stage renal disease (ESRD) patients [51].

In the early stages of CKD, patients maintain an ample capacity to eliminate high potassium load from the diet, so hyperkalemia does not usually occur and the external potassium balance is generally neutral, unless therapies changing the internal balance or impairing renal excretion capacity are administered. This is a crucial point, because high potassium diets have been associated with positive cardiovascular (CV) and renal outcomes in CKD patients [52]. Hence, proper dietary counseling is mandatory in CKD patients with chronic hyperkalemia as in those with sporadic hyperkalemic episodes [48].

Special attention must also be paid to avoid excess potassium load, together with the maintenance of a high fiber intake and a low net fixed-acid production. This is important since constipation and metabolic acidosis are major risk factors for chronic hyperkalemia [51].

In order to achieve a lower potassium intake without a decrease in fiber and alkali intake, some home-based lowcost pragmatic suggestions may be provided. The first step is the availability and awareness of information on the type of foods which contain excess potassium for serving or for unit of weight, which should be avoided. Another tool for food selection may be based on the potassium content normalized for unit of fiber, namely the reporting of the potassium content of vegetables and fruits also as "mg per $1 \mathrm{~g}$ fiber" [48]. An additional suggestion to limit potassium intake is the use of cooking procedures (e.g. soaking or boiling) that allow food demineralization: boiling can remove up to $60-80 \%$ of potassium content from several raw foods [53, 54].

Attention should be paid to hidden sources of potassium, such as certain food additives [55] and, in particular, salt substitutes. The latter represents a significant potassium load on top of the potassium coming from food, which is of concern in patients with reduced capacity of potassium excretion. In low-sodium salts, sodium-chloride content must not exceed $35 \%$ (corresponding to a sodium content not $>13.6 \%$ ) and cannot be less than $20 \%$ (corresponding to a sodium content not $<7.8 \%$ ) with a potassium:sodium ratio of 1.5:1 at least. This means that 5-6 $\mathrm{g}$ of a current salt substitute can supply up to $1500-1800 \mathrm{mg}$ (38-46 mmol) of extra-potassium [48].

Although no human study is available to date, dietary counseling can be effective for the prevention and treatment of hyperkalemia. From a pathophysiology basis, the limitation of potassium intake counteracts the tendency to positive external potassium balance in CKD $[47,56]$. It is conceivable that the effective reduction of dietary potassium intake is an important tool in the treatment of chronic hyperkalemia; however, it is not common practice because it is time-consuming and difficult to perform in a real-life clinical setting. Poor dietary education given to health care providers is a frequent additional reason [47].

Pragmatic interventions to lower potassium load without inducing a decrease in alkali or fiber intake, therefore, are: (a) identify foods that contain excess potassium load, (b) prefer foods that supply a low amount of potassium both as absolute value and as normalized per unit of fiber content, (c) educate patients on the use of cooking procedures (especially boiling) in order to remove potassium, and (d) avoid hidden sources of potassium (e.g. food additives and low-sodium salt substitutes).

\section{Rationale for intensive (and potentially hyperkalemic) anti-RAAS therapy}

Current nephrology guidelines recommend anti-RAAS in patients with urine albumin excretion $>300 \mathrm{mg} / 24 \mathrm{~h}$ or proteinuria $>500 \mathrm{mg} / 24 \mathrm{~h}$ [15]. This " $1 \mathrm{~B}$ " recommendation is based on the proven nephroprotective efficacy of these agents in proteinuric patients. A subsequent meta-regression analysis has supported this rationale by revealing that the risk of ESRD decreases by $24 \%$ for each $30 \%$ reduction in albuminuria, with clinical meaningful efficacy observed for anti-RAAS [57]. The positive effect of these drugs in delaying ESRD has also been verified by a network meta-analysis of randomized clinical trials [58], and even confirmed in advanced disease [59]. It is worth noting that anti-RAAS also affords a survival benefit; analyses in a large cohort of older patients, most with CKD stage 3 and albuminuria, have in fact shown that anti-RAAS therapy yields a $19 \%$ lower risk of mortality [60]. This finding extends to overt CKD; the post-hoc analysis of the LIFE trial in hypertensive individuals with mild CKD showed that the level of CV protection was proportional to the degree of albuminuria reduction [61]. Interestingly, anti-RAAS agents can also improve CV prognosis in non-albuminuric patients [62, 63]. Conversely, 
in the growing population of patients with proteinuria less than $0.5 \mathrm{~g} / 24 \mathrm{~h}$ [64], the nephroprotective effects of antiRAAS are less evident or even absent [65, 66].

Therefore, anti-RAAS drugs are the primary therapeutic tools used to improve renal prognosis in proteinuric patients, as indicated by current guidelines [15]. Experimental studies have indeed demonstrated that albumin tubular overload sustains a sequence of inflammatory events leading to tissue scarring and eGFR loss, while anti-RAAS delays progression of kidney damage and dysfunction by lowering glomerular pressure and restoring glomerular sieving function. With regard to the association with cardiovascular risk, it is possible that albuminuria may simply act as a marker of endothelial dysfunction [67-69].

Guidelines identify a proteinuria level of $0.5 \mathrm{~g} / 24 \mathrm{~h}$ as a major goal of antiproteinuric therapy [15]. Nevertheless, almost half of patients under stable nephrology care including anti-RAAS therapy do not reach this target in renal clinics despite evidence that even residual proteinuria portends a significant excess risk of ESRD [70, 71]. Therefore, while nephrologists should pursue the goal of minimizing proteinuria, this target is de facto hardly achievable.

Two major reasons account for this therapeutic failure. First, side effects of anti-RAAS restrain their use. Specifically, a clinically significant acute kidney injury (AKI) in the course of anti-RAAS monotherapy, which is dependent on GFR worsening due to underlying (and often undiagnosed) ischemic nephropathy, occurs in less than $2 \%$ of CKD patients, particularly those under diuretics [72]; however, incidence rates markedly increase in the presence of dual blockade of RAAS [73]. Hyperkalemia is more common than AKI with an incidence ranging from 5 to $40 \%$, and, moreover, it acts as a main driver for anti-RAAS withdrawal $[8,13,30]$.

Second, the high complexity of the RAAS with multiplelevel escape mechanisms prevents adequate suppression by anti-RAAS monotherapy that allows only a $30 \%$ reduction on average. Multiple-level blockade of RAAS has been in fact tested to overcome escape pathways. This approach, though more effective in reducing albuminuria, and probably the ESRD risk as well, is associated with a slightly greater risk of AKI and can even double the risk of hyperkalemia versus single-drug therapy [74-77]. An alternative option to dual blockade in diabetic CKD may be the association of a single anti-RAAS agent with an inhibitor of renal sodium-glucose cotransporter-2 (SGLT2-i); recent studies have in fact shown that the SGLT2-I dapaglifozin reduces per se albuminuria without increasing risk of hyperkalemia and AKI in diabetics with normal or mildly impaired renal function $[78,79]$. Nevertheless, long-term trials are needed to verify the nephroprotective effectiveness of SGLT2-I in patients with overt CKD.
Therefore, it is possible to conclude that in proteinuric patients: (a) anti-RAAS therapy titrated to maximize reduction of proteinuria in CKD patients has a solid pathophysiological rationale and proven nephroprotective efficacy, and (b) in clinical practice, the treat-to-target approach is limited due to multiple-level escape mechanisms, as well as by side effects of therapy, the main being hyperkalemia.

\section{Downtitration of anti-RAAS as intervention in chronic HF or diabetic patients with CKD and hyperkalemia}

RAAS blockade is the cornerstone of cardioprotection in chronic heart failure (CHF) and of renoprotection in diabetic kidney disease (DKD). Furthermore, RAAS blockers have shown to be effective in reversing cardiomyopathy and improving CV outcome of renal patients [80, 81]. However, there is concern about its systematic adoption in patients with reduced GFR because of the risk of worsening renal function and hyperkalemia [73].

NICE guidelines recommend not to offer anti-RAAS to CKD patients if pre-treatment $\mathrm{sK}$ is $>5.0 \mathrm{mEq} / \mathrm{l}$, and to withdraw therapy when $\mathrm{sK}$ increases to $6.0 \mathrm{mEq} / 1$ [17]. In clinical practice, detection of $\mathrm{sK}>5.5 \mathrm{mEq} / \mathrm{l}$ leads to a $5 \%$ dose reduction but even a $25 \%$ discontinuation of anti-RAAS in 194,456 outpatients included in the Geisinger Health System [8]. However, the problem is even more compelling for MRAs with a rate of discontinuation in up to half of patients administered this class of medication [8].

It is conceivable that downtitration or even withdrawal of anti-RAAS for safety reasons, although resulting in better control of sK, misses the opportunity of offering high risk patients the best available therapy for DKD or CHF. In fact, most CKD patients are not receiving adequate doses of these drugs due to hyperkalemia, and this is not to be underestimated, in that it is associated with increased incidence of adverse events and mortality [82]. This is especially true for MRAs that are used as add-on therapy for refractory CHF [83], and they have also shown to be effective in reducing proteinuria and slowing renal disease progression [84].

Indeed, NICE guidelines point out the importance of assessment, treatment, and eventual discontinuation of other factors or medications that can induce hyperkalemia in CKD high risk patients taking anti-RAAS [17]. Correction of metabolic acidosis by alkali assumption, and adherence to a low potassium diet could help in preventing hyperkalemia in these patients [85]. However, patient adherence is a major concern. Systematic use of diuretic therapy, especially in the outpatient setting management, could induce chronic hypovolemia and subsequent worsening of renal function, and chronic therapy with sodium polystyrene sulfonate (SPS) is burdened by side effects, often severe [86-88]. 
Therefore, even though downtitration or even withdrawal of anti-RAAS is a frequent strategy in the event of hyperkalemia in CKD patients with DKD and/or CHF, it is wise to offset other factors or to stop any other medication that can induce hyperkalemia.

\section{Pitfalls of current therapy of hyperkalemia in CKD}

Careful monitoring of eGFR and sK levels should be regarded as the "core" of CKD management with antiRAAS agents [82]. The two measures are indeed generally linked, due to the strict dependence of sK on GFR level. Treatment of hyperkalemia becomes even more important when considering that a mild-to-moderate reduction of GFR is expected when anti-RAAS therapy is started or uptitrated in proteinuric patients $[30,82,89,90]$.

A stepwise practical management approach to control sK levels in a renal clinic is depicted in Fig. 2. Treatment is multifaceted, with monitoring (including careful revision of drugs that potentially increase sK) and dietary counseling being the basic features. Oral supplementation of bicarbonate is only indicated in the presence of metabolic acidosis; similarly, more intensive control of glucose levels in diabetics is functional to favor cellular inflow of potassium with glucose. Patients will also take advantage from uptitration of the thiazide dose or a switch to loop diuretics correctly dosed according to eGFR value. Potassium-binding resins are generally prescribed when all the above interventions are not effective in controlling sK at levels $\leq 5.5 \mathrm{mEq} / \mathrm{l}$. If levels persist above $6.5 \mathrm{mEq} / \mathrm{l}$ and symptoms (fatigue) and signs (ECG) develop, more aggressive therapy, including dialysis, is indicated.

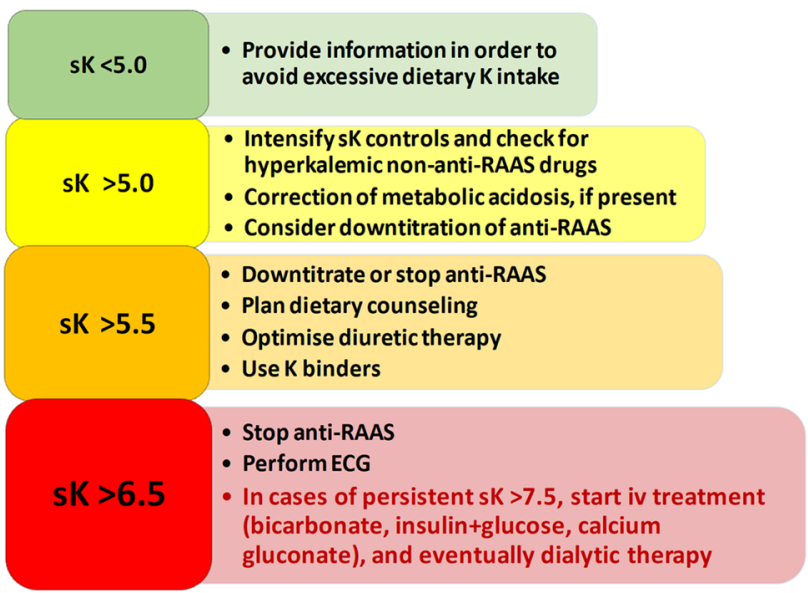

Fig. 2 Stepwise approach to hyperkalemia in CKD patients under nephrology care. $K$ potassium, $s K$ serum potassium $(\mathrm{mEq} / \mathrm{l})$, anti$R A A S$ antagonists of renin-angiotensin-aldosterone system, $i v$ intravenous, $E C G$ electrocardiogram
Remarkably, however, the main interventions included in this "nephrologist" algorithm can often be ineffective.

\section{Diet modification}

Besides the common observation that patients are poorly compliant to prescribed changes in diet, available data do not support a consistent effect of restriction of potassium intake on sK levels [51]. On the other hand, a recent analysis of Modification of Diet in Renal Disease Study in non-diabetic patients with overt CKD has shown that higher dietary intake of potassium is associated with a lower risk for all-cause mortality [91]. Ad hoc clinical trials are therefore needed in CKD to verify whether restricting fruits/vegetables is truly effective in controlling sK and, more importantly, if it is associated with poor survival, as evidenced in the non-CKD population [92].

\section{Diuretic therapy}

Intensification of diuretic therapy in anti-RAAS treated patients is safe and efficacious only in the presence of discrete extracellular volume expansion; conversely, uptitrating diuretic therapy in hypovolemic or euvolemic patients can lead to excessive lowering of renal perfusion and function [93], which, in turn, causes an increase in sK levels. In this regard, strict monitoring of blood pressure can be helpful [94].

\section{Potassium binding}

SPS has been used in the last five decades as the cornerstone for the treatment of chronic hyperkalemia by inducing watery diarrhea with dependent potassium loss. However, the long term efficacy of SPS has not been evaluated in randomized, placebo-controlled trials. Moreover, it has been typically used in hospitals and less frequently in the outpatient setting due to low tolerability [86-88, 95]. In 2009, in fact, the US Food and Drug Administration posted a warning because of reported cases of colonic necrosis, bleeding, ischemic colitis, and perforation related to SPS [87]. Of note, in 2009 the FDA warned clinicians about adverse events occurring with SPS especially if premixed with sorbitol (that is the suspension commonly marketed in some countries) [96].

Calcium polystyrene sulfonate (CPS) is the other available $\mathrm{K}$ binder that has an advantage over SPS because, at variance with SPS, it avoids sodium retention by entrapping potassium in the distal colon in exchange for calcium. However, it is less used in nephrology practice than SPS, while it shares with SPS the paucity of data on usefulness and tolerability. Recently, a study was published on the longterm efficacy of oral CPS for treating mild hyperkalemia in 
247 adult patients with baseline eGFR level of $30 \pm 15 \mathrm{ml} /$ $\mathrm{min} / 1.73 \mathrm{~m}^{2}$ [97]. The findings suggested that CPS is effective and safe for controlling mild hyperkalemia in CKD. However, interpretation of this study is limited by the retrospective nature of the analysis, the use of electronic medical records, small sample size, inclusion of only Asian patients and the absence of any data on serum calcium.

The limitations of current treatment of hyperkalemia likely are the cause of the large number of anti-RAAS treated patients found to be hyperkalemic both in renal clinics and even in the ideal setting of randomized clinical trials. Therefore, there is an important unmet need for a welltolerated therapy to control sK over the long term in CKD patients who require adequate RAAS blockade.

Therefore, the current approach to control sK in renal clinics is based on multi-target therapy. Aside from bicarbonate supplementation (indicated only in the presence of acidosis), the main components are the restriction of dietary potassium intake, intensive diuretic therapy and potassium binding. However, each of these three interventions is burdened by low efficacy and substantial side effects.

\section{Novel therapies to control sK in patients under anti-RAAS therapy}

Until the FDA approval of patiromer in 2015 and the appearance of sodium zirconium cyclosilicate (ZS-9), the treatment of hyperkalemia in a chronic setting had remained unchanged for many years. These two new potassium-binding agents appear to have the potential to optimize control of chronic hyperkalemia and therefore enable optimal antiRAAS therapy (Table 3). Here we report the main results of trials on the two new drugs, that can be useful for the clinical nephrologist while awaiting real-world data on a larger number of patients treated for a longer period of time.

\section{Patiromer}

Patiromer is a non-absorbed polymer that binds potassium in exchange for calcium throughout the gastrointestinal tract, resulting in an increase in intestinal secretion of potassium with a consequent reduction of sK levels. Patiromer is stable and nonsystemically absorbed and has been extensively studied in patients with CKD and/or cardiovascular disease [98].

The phase 3 study conducted by Weir et al. was designed to examine CKD patients with hyperkalemia (sK 5.1-6.5 mEq/l) treated with anti-RAAS, and randomized to patiromer or placebo [21]. A significant reduction in sK in the patiromer arm was observed in the first 4 weeks. The second phase of the study involved patients with baseline sK $5.5-6.5 \mathrm{mEq} / 1$; levels decreased to $3.8-5.1 \mathrm{mEq} / 1$ following treatment with patiromer. These patients then entered into an 8 -week randomized withdrawal phase in which they either continued on patiromer or switched to placebo. In this phase, a significant difference in $\mathrm{sK}$ change $(0.72 \mathrm{mEq} / \mathrm{l}$ increase in placebo vs. 0 in patiromer) was observed. It is worth noting that over $90 \%$ of patients with $\mathrm{sK}>5.5 \mathrm{mEq} / \mathrm{l}$ at baseline were able to remain on anti-RAAS therapy, while less than $50 \%$ of patients who were switched to placebo maintained the RAAS-blocking drug [21].

Interestingly, more than half the study participants had diabetes, eGFR $<30 \mathrm{ml} / \mathrm{min} / 1.73 \mathrm{~m}^{2}$ and $40 \%$ had CHF. The mean age of patients enrolled in the study was nearly 65 years. Therefore, the study population was a high-risk group that was successfully maintained on the indicated

Table 3 Characteristics of potassium-binding agents for the treatment of hyperkalemia

\begin{tabular}{|c|c|c|c|}
\hline Characteristic & SPS [86-88] & Patiromer $[98,101,102]$ & ZS-9 [103, 104] \\
\hline Molecule & $\begin{array}{l}\text { Nonspecific, sodium-containing, } \\
\text { organic resin }\end{array}$ & $\begin{array}{l}\text { Selective, sodium-free, organic } \\
\text { polymer }\end{array}$ & $\begin{array}{l}\text { Selective, sodium-containing, inor- } \\
\text { ganic crystalline silicate }\end{array}$ \\
\hline Mechanism of action & $\begin{array}{l}\text { Nonspecific binding of potassium in } \\
\text { exchange for sodium }\end{array}$ & $\begin{array}{l}\text { Nonspecific binding of potassium in } \\
\text { exchange for calcium }\end{array}$ & $\begin{array}{l}\text { Selective potassium binding in } \\
\text { exchange for sodium }\end{array}$ \\
\hline Administration/formulation & Oral or rectal suspension & Oral suspension & Oral suspension \\
\hline Site of action & Colon & Distal colon & Entire intestinal tract \\
\hline Onset of effect & $1-2 \mathrm{~h}$ & $7 \mathrm{~h}$ & $1 \mathrm{~h}$ \\
\hline Dosing & $\begin{array}{l}15-60 \mathrm{~g} / \text { day orally; } 30-50 \mathrm{~g} / \text { day } \\
\text { rectally }\end{array}$ & $8.4-25.2 \mathrm{~g} /$ day & $\begin{array}{l}2.5-30 \mathrm{~g} / \text { day depending on the acute/ } \\
\text { chronic situation }\end{array}$ \\
\hline Common adverse events & $\begin{array}{l}\text { Gastrointestinal disorders } \\
\text { Hypernatremia } \\
\text { Hypokalemia } \\
\text { Alkalosis } \\
\text { Volume overload }\end{array}$ & $\begin{array}{l}\text { Gastrointestinal disorders } \\
\text { Hypokalemia } \\
\text { Hypomagnesemia }\end{array}$ & $\begin{array}{l}\text { Gastrointestinal disorders } \\
\text { Hypokalemia } \\
\text { Edema }\end{array}$ \\
\hline Serious adverse events & Colonic necrosis & None & None \\
\hline
\end{tabular}

GI gastrointestinal, SPS sodium polystyrene sulfonate, ZS-9 sodium zirconium cyclosilicate 
anti-RAAS therapy. Patiromer was well tolerated throughout the study, constipation being the only adverse event with a reported frequency of $>3 \%$.

Similar effects have been demonstrated in a long-term clinical trial in patients with type 2 diabetes [22]. Interestingly, a significant reduction in mean systolic and diastolic blood pressure was also observed in this trial. This effect could be related to the maintenance of RAAS-blocking therapy, better adherence to antihypertensive therapy during the course of the study or the possibility that patiromer may be associated with intestinal sodium binding. The blood pressure-lowering effect is supported by the phase 3 OPALHK study where patients randomized to patiromer had a significant reduction in mean systolic/diastolic blood pressure in association with decreasing aldosterone levels [99]. Nonetheless, in CKD patients, higher K excretion (testifying higher intake) is associated with increased risk of CKD progression [100]. Therefore, future studies on the novel K-binders indicated for chronic therapy should verify the long-term effects on CKD progression. Hypomagnesemia was the most common treatment-related adverse event (7.2\%), but no patient developed severe hypomagnesemia.

Patiromer has also been studied to determine its onset of action in patients with CKD receiving anti-RAAS treatment [101]. After a 3-day potassium- and sodium-restricted diet in an inpatient general clinical research unit, 25 patients with sustained hyperkalemia (5.5-6.4 mEq/l) received patiromer $8.4 \mathrm{~g}$ twice daily. Mean baseline sK was $5.93 \mathrm{mEq} / \mathrm{l}$, and decreased significantly $7 \mathrm{~h}$ after the first dose of the drug and at all subsequent assessments through $48 \mathrm{~h}$. At $48 \mathrm{~h}(14 \mathrm{~h}$ after the last dose), the mean reduction was $-0.75 \mathrm{mEq} / \mathrm{l}$ [101]. Of note, due to potential drug-drug interactions, the administration of other oral medications should be at least $3 \mathrm{~h}$ before or $3 \mathrm{~h}$ after administration of patiromer [102].

\section{ZS-9}

ZS-9 is an insoluble, highly stable and non-systemically absorbed inorganic sodium-potassium cation exchange drug, currently undergoing clinical evaluation as a potential treatment for hyperkalemia [103, 104]. Two phase 3 trials have been completed, and a third is currently investigating long-term therapy. Overall, these studies have demonstrated that ZS-9 is an effective potassium binder that corrects hyperkalemia with a dose-dependent effect within $48 \mathrm{~h}$ of treatment. The reduction in $\mathrm{sK}$ is most pronounced in patients with higher baseline levels, and ZS-9 is effective in normalizing kalemia in patients, whether or not they are receiving anti-RAAS therapy [20,103]. Adverse events have been found to be comparable in ZS-9 and placebo, although edema is more frequent in patients treated with the drug.

Patiromer and ZS-9 therefore appear to be effective and well tolerated drugs that can be used to reduce sK levels consistently and safely. The recent FDA approval of patiromer, and the expected approval of ZS-9, should allow an opportunity for clinicians to use recommended and appropriate doses of anti-RAAS agents in patients with CKD and cardiovascular disease, particularly allowing a wider use of MRAs that may have important additive benefits when administered in association with traditional RAAS-blocking drugs.

It is worth noting that European guidelines for the diagnosis and treatment of HF have recently highlighted the results of patiromer and ZS-9 studies in patients with CHF as they confirm the efficacy of these new therapies in reducing sK and preventing recurrent hyperkalemia in patients with $\mathrm{CHF}$ and CKD, in the context of anti-RAAS treatment [83].

Acknowledgements The authors are grateful to Dr Colin Gerard Egan (CE-Medical Writing, Pisa, Italy) for editorial assistance in the preparation of this manuscript.

\section{Compliance with ethical standards}

Conflict of interest LDN has received payment for lectures and/or scientific consultancy from Amgen, Abbvie, Astrazeneca, Vifor Fresenius, Janssen and Roche. AC, EP and LDL have received consultant fees from Vifor Fresenius. SB has no conflict of interest to declare.

Ethical approval For this type of study formal consent is not required. This article does not contain any studies with humans or animals performed by any of the authors.

Open Access This article is distributed under the terms of the Creative Commons Attribution 4.0 International License (http://creativeco mmons.org/licenses/by/4.0/), which permits unrestricted use, distribution, and reproduction in any medium, provided you give appropriate credit to the original author(s) and the source, provide a link to the Creative Commons license, and indicate if changes were made.

\section{References}

1. Levey AS, Andreoli SP, DuBose T et al (2007) Chronic kidney disease: common, harmful, and treatable-World Kidney Day 2007. Clin J Am Soc Nephrol 2:401-405. https://doi. org/10.2215/CJN.04041206

2. Pacilio M, Minutolo R, Garofalo C et al (2016) Stage 5-CKD under nephrology care: to dialyze or not to dialyze, that is the question. J Nephrol 29:153-161. https://doi.org/10.1007/s4062 $0-015-0243-8$

3. Hayes J, Kalantar-Zadeh K, Lu JL et al (2012) Association of hypo- and hyperkalemia with disease progression and mortality in males with chronic kidney disease: the role of race. Nephron Clin Pract 120:c8-16. https://doi.org/10.1159/000329511

4. Drawz PE, Babineau DC, Rahman M (2012) Metabolic complications in elderly adults with chronic kidney disease. J Am Geriatr Soc 60:310-315. https://doi.org/10.111 1/j.1532-5415.2011.03818.x

5. Sarafidis PA, Blacklock R, Wood E et al (2012) Prevalence and factors associated with hyperkalemia in predialysis patients 
followed in a low-clearance clinic. Clin J Am Soc Nephrol 7:1234-1241. https://doi.org/10.2215/CJN.01150112

6. Nakhoul GN, Huang H, Arrigain S et al (2015) Serum potassium, end-stage renal disease and mortality in chronic kidney disease. Am J Nephrol 41:456-463. https://doi.org/10.1159/000437151

7. Luo J, Brunelli SM, Jensen DE, Yang A (2016) Association between serum potassium and outcomes in patients with reduced kidney function. Clin J Am Soc Nephrol 11:90-100. https://doi.org/10.2215/CJN.01730215

8. Chang AR, Sang Y, Leddy J et al (2016) Antihypertensive medications and the prevalence of hyperkalemia in a large health system. Hypertens Dallas Tex 1979 67:1181-1188. https ://doi.org/10.1161/HYPERTENSIONAHA.116.07363

9. Hughes-Austin JM, Rifkin DE, Beben T et al (2017) The relation of serum potassium concentration with cardiovascular events and mortality in community-living individuals. Clin J Am Soc Nephrol 12:245-252. https://doi.org/10.2215/CJN.06290616

10. Betts KA, American Society of Nephrology I Kidney Week Abstract Details. https://www.asn-online.org/education/kidne yweek $/ 2017 /$ program-abstract.aspx ? controlId=2785026. Accessed 21 Jan 2018

11. Núñez J, Bayés-Genís A, Zannad F et al (2017) Long-term potassium monitoring and dynamics in heart failure and risk of mortality. Circulation. https://doi.org/10.1161/CIRCULATIO NAHA.117.030576

12. Collins AJ, Pitt B, Reaven N et al (2017) Association of serum potassium with all-cause mortality in patients with and without heart failure, chronic kidney disease, and/or diabetes. Am J Nephrol 46:213-221. https://doi.org/10.1159/000479802

13. Kovesdy CP (2016) Epidemiology of hyperkalemia: an update. Kidney Int Suppl 6:3-6. https://doi.org/10.1016/j. kisu.2016.01.002

14. van de Luijtgaarden MWM, Noordzij M, Tomson C et al (2012) Factors influencing the decision to start renal replacement therapy: results of a survey among European nephrologists. Am J Kidney Dis 60:940-948. https://doi.org/10.1053/j. ajkd.2012.07.015

15. Kellum JA, Lameire N, Aspelin P et al (2012) KDIGO 2012. Kidney Int 2:1

16. Fitch K, Woolley JM, Engel T, Blumen H (2017) The clinical and economic burden of hyperkalemia on medicare and commercial payers. Am Health Drug Benefits 10:202-210

17. National Clinical Guideline Centre (UK) (2014) Chronic kidney disease (partial update): early identification and management of chronic kidney disease in adults in primary and secondary care. National Institute for Health and Care Excellence (UK), London

18. Moranne O, Froissart M, Rossert J et al (2009) Timing of onset of CKD-related metabolic complications. J Am Soc Nephrol 20:164-171. https://doi.org/10.1681/ASN.2008020159

19. Loutradis C, Tolika P, Skodra A et al (2015) Prevalence of hyperkalemia in diabetic and non-diabetic patients with chronic kidney disease: a nested case-control study. Am J Nephrol 42:351-360. https://doi.org/10.1159/000442393

20. Kosiborod M, Rasmussen HS, Lavin P et al (2014) Effect of sodium zirconium cyclosilicate on potassium lowering for 28 days among outpatients with hyperkalemia: the HARMONIZE randomized clinical trial. JAMA 312:2223-2233. https://doi. org/10.1001/jama.2014.15688

21. Weir MR, Bakris GL, Bushinsky DA et al (2015) Patiromer in patients with kidney disease and hyperkalemia receiving RAAS inhibitors. N Engl J Med 372:211-221. https://doi.org/10.1056/ NEJMoa1410853

22. Bakris GL, Pitt B, Weir MR et al (2015) Effect of patiromer on serum potassium level in patients with hyperkalemia and diabetic kidney disease: the AMETHYST-DN randomized clinical trial. JAMA 314:151-161. https://doi.org/10.1001/jama.2015.7446
23. Korgaonkar S, Tilea A, Gillespie BW et al (2010) Serum potassium and outcomes in CKD: insights from the RRI-CKD cohort study. CLIN J Am Soc Nephrol 5:762-769. https://doi. org/10.2215/CJN.05850809

24. Asirvatham JR, Moses V, Bjornson L (2013) Errors in potassium measurement: a laboratory perspective for the clinician. N Am J Med Sci 5:255-259. https://doi.org/10.4103/19472714.110426

25. Mohanlal V, Haririan A, Weinman EJ (2013) Bradycardia without "classical" EKG changes in hyperkalemic hemodialysis patients. Clin Nephrol 80:464-468. https://doi.org/10.5414/ CN107529

26. McIntyre WF, Femenía F, Arce M et al (2011) Importance of early electrocardiographic recognition and timely management of hyperkalemia in geriatric patients. Exp Clin Cardiol $16: 47-50$

27. Montague BT, Ouellette JR, Buller GK (2008) Retrospective review of the frequency of ECG changes in hyperkalemia. Clin J Am Soc Nephrol 3:324-330. https://doi.org/10.2215/CJN.04611 007

28. Durfey N, Lehnhof B, Bergeson A et al (2017) Severe hyperkalemia: can the electrocardiogram risk stratify for short-term adverse events? West J Emerg Med 18:963-971. https://doi. org/10.5811/westjem.2017.6.33033

29. Khan SS, Campia U, Chioncel O et al (2015) Changes in serum potassium levels during hospitalization in patients with worsening heart failure and reduced ejection fraction (from the EVEREST trial). Am J Cardiol 115:790-796. https://doi.org/10.1016/j. amjcard.2014.12.045

30. Bandak G, Sang Y, Gasparini A et al (2017) Hyperkalemia after initiating renin-angiotensin system blockade: the Stockholm creatinine measurements (SCREAM) project. J Am Heart Assoc. https://doi.org/10.1161/JAHA.116.005428

31. Palmer BF (2004) Managing hyperkalemia caused by inhibitors of the renin-angiotensin-aldosterone system. N Engl J Med 351:585-592. https://doi.org/10.1056/NEJMra035279

32. Michel A, Martín-Pérez M, Ruigómez A, García Rodríguez LA (2015) Risk factors for hyperkalaemia in a cohort of patients with newly diagnosed heart failure: a nested case-control study in UK general practice. Eur J Heart Fail 17:205-213. https://doi. org/10.1002/ejhf.226

33. Vardeny O, Claggett B, Anand I et al (2014) Incidence, predictors, and outcomes related to hypo- and hyperkalemia in patients with severe heart failure treated with a mineralocorticoid receptor antagonist. Circ Heart Fail 7:573-579. https://doi.org/10.1161/ CIRCHEARTFAILURE.114.001104

34. Adams KF, Fonarow GC, Emerman CL et al (2005) Characteristics and outcomes of patients hospitalized for heart failure in the United States: rationale, design, and preliminary observations from the first 100,000 cases in the Acute Decompensated Heart Failure National Registry (ADHERE). Am Heart J 149:209-216. https://doi.org/10.1016/j.ahj.2004.08.005

35. DeFronzo RA (1980) Hyperkalemia and hyporeninemic hypoaldosteronism. Kidney Int 17:118-134

36. Bellizzi V, Cupisti A, Locatelli F et al (2016) Low-protein diets for chronic kidney disease patients: the Italian experience. BMC Nephrol 17:77. https://doi.org/10.1186/s12882-016-0280-0

37. Bellizzi V, Bianchi S, Bolasco P et al (2016) A Delphi consensus panel on nutritional therapy in chronic kidney disease. J Nephrol 29:593-602. https://doi.org/10.1007/s40620-016-0323-4

38. Di Iorio BR, Cupisti A, D'Alessandro C et al (2018) Nutritional therapy in autosomal dominant polycystic kidney disease. J Nephrol. https://doi.org/10.1007/s40620-018-0470-x

39. Cupisti A, D’Alessandro C, Gesualdo L et al (2017) Non-traditional aspects of renal diets: focus on fiber, alkali and vitamin K1 intake. Nutrients. https://doi.org/10.3390/nu9050444 
40. Sabatino A, Regolisti G, Gandolfini I et al (2017) Diet and enteral nutrition in patients with chronic kidney disease not on dialysis: a review focusing on fat, fiber and protein intake. J Nephrol 30:743-754. https://doi.org/10.1007/s40620-017-0435-5

41. Barsotti G, Morelli E, Cupisti A et al (1996) A low-nitrogen lowphosphorus Vegan diet for patients with chronic renal failure. Nephron 74:390-394

42. Cupisti A, Morelli E, Meola M et al (2002) Vegetarian diet alternated with conventional low-protein diet for patients with chronic renal failure. J Ren Nutr 12:32-37

43. Di Iorio BR, Di Micco L, Marzocco S et al (2017) Very lowprotein diet (VLPD) reduces metabolic acidosis in subjects with chronic kidney disease: the "nutritional light signal" of the renal acid load. Nutrients. https://doi.org/10.3390/nu9010069

44. Moorthi RN, Armstrong CLH, Janda K et al (2014) The effect of a diet containing $70 \%$ protein from plants on mineral metabolism and musculoskeletal health in chronic kidney disease. Am J Nephrol 40:582-591. https://doi.org/10.1159/000371498

45. K/DOQI, National Kidney Foundation (2000) Clinical practice guidelines for nutrition in chronic renal failure. Am J Kidney Dis 35:S1-S40

46. Kalantar-Zadeh K, Fouque D (2017) Nutritional management of chronic kidney disease. N Engl J Med 377:1765-1776. https:// doi.org/10.1056/NEJMra1700312

47. Montford JR, Linas S (2017) How dangerous is hyperkalemia? J Am Soc Nephrol 28:3155-3165. https://doi.org/10.1681/ ASN.2016121344

48. Cupisti A, Kovesdy CP, D’Alessandro C, Kalantar-Zadeh K (2018) Dietary approach to recurrent or chronic hyperkalaemia in patients with decreased kidney function. Nutrients 10:261. https://doi.org/10.3390/nu10030261

49. van Ypersele de Strihou C (1977) Potassium homeostasis in renal failure. Kidney Int 11:491-504

50. Agarwal R, Afzalpurkar R, Fordtran JS (1994) Pathophysiology of potassium absorption and secretion by the human intestine. Gastroenterology 107:548-571

51. St-Jules DE, Goldfarb DS, Sevick MA (2016) Nutrient nonequivalence: does restricting high-potassium plant foods help to prevent hyperkalemia in hemodialysis patients? J Ren Nutr 26:282-287. https://doi.org/10.1053/j.jrn.2016.02.005

52. Palmer BF, Clegg DJ (2016) Achieving the benefits of a highpotassium, paleolithic diet, without the toxicity. Mayo Clin Proc 91:496-508. https://doi.org/10.1016/j.mayocp.2016.01.012

53. Jones WL (2001) Demineralization of a wide variety of foods for the renal patient. J Ren Nutr 11:90-96

54. Picq C, Asplanato M, Bernillon N et al (2014) Effects of water soaking and/or sodium polystyrene sulfonate addition on potassium content of foods. Int J Food Sci Nutr 65:673-677. https:// doi.org/10.3109/09637486.2014.908172

55. Parpia AS, L'Abbé M, Goldstein M et al (2017) The impact of additives on the phosphorus, potassium, and sodium content of commonly consumed meat, poultry, and fish products among patients with chronic kidney disease. J Ren Nutr. https://doi. org/10.1053/j.jrn.2017.08.013

56. Kovesdy CP, Appel LJ, Grams ME et al (2017) Potassium homeostasis in health and disease: a scientific workshop cosponsored by the National Kidney Foundation and the American Society of Hypertension. J Am Soc Hypertens 11:783-800. https://doi. org/10.1016/j.jash.2017.09.011

57. Heerspink HJL, Kröpelin TF, Hoekman J et al (2015) Druginduced reduction in albuminuria is associated with subsequent renoprotection: a meta-analysis. J Am Soc Nephrol 26:20552064. https://doi.org/10.1681/ASN.2014070688

58. Xie X, Liu Y, Perkovic V et al (2016) Renin-angiotensin system inhibitors and kidney and cardiovascular outcomes in patients with CKD: a Bayesian network meta-analysis of randomized clinical trials. Am J Kidney Dis 67:728-741. https://doi. org/10.1053/j.ajkd.2015.10.011

59. Hsu T-W, Liu J-S, Hung S-C et al (2014) Renoprotective effect of renin-angiotensin-aldosterone system blockade in patients with predialysis advanced chronic kidney disease, hypertension, and anemia. JAMA Intern Med 174:347-354. https://doi. org/10.1001/jamainternmed.2013.12700

60. Molnar MZ, Kalantar-Zadeh K, Lott EH et al (2014) Angiotensin-converting enzyme inhibitor, angiotensin receptor blocker use, and mortality in patients with chronic kidney disease. J Am Coll Cardiol 63:650-658. https://doi.org/10.1016/j. jacc.2013.10.050

61. Ibsen H, Olsen MH, Wachtell $\mathrm{K}$ et al (2005) Reduction in albuminuria translates to reduction in cardiovascular events in hypertensive patients: losartan intervention for endpoint reduction in hypertension study. Hypertens Dallas Tex 1979 45:198-202. https://doi.org/10.1161/01.HYP.0000154082.72286.2a

62. Ruggenenti P, Porrini E, Motterlini N et al (2012) Measurable urinary albumin predicts cardiovascular risk among normoalbuminuric patients with type 2 diabetes. J Am Soc Nephrol 23:1717-1724. https://doi.org/10.1681/ASN.2012030252

63. Torres VE, Abebe KZ, Chapman AB et al (2014) Angiotensin blockade in late autosomal dominant polycystic kidney disease. N Engl J Med 371:2267-2276. https://doi.org/10.1056/NEJMo a1402686

64. Bolignano D, Zoccali C (2017) Non-proteinuric rather than proteinuric renal diseases are the leading cause of end-stage kidney disease. Nephrol Dial Transplant 32:ii194-ii199. https://doi. org/10.1093/ndt/gfw440

65. Kent DM, Jafar TH, Hayward RA et al (2007) Progression risk, urinary protein excretion, and treatment effects of angiotensinconverting enzyme inhibitors in nondiabetic kidney disease. J Am Soc Nephrol 18:1959-1965. https://doi.org/10.1681/ ASN.2006101081

66. Ponticelli C, Cucchiari D (2017) Renin-angiotensin system inhibitors in kidney transplantation: a benefit-risk assessment. J Nephrol 30:155-157. https://doi.org/10.1007/s40620-017-0378-x

67. Deckert T, Feldt-Rasmussen B, Borch-Johnsen K et al (1989) Albuminuria reflects widespread vascular damage. The steno hypothesis. Diabetologia 32:219-226

68. Jensen JS, Borch-Johnsen K, Jensen G, Feldt-Rasmussen B (1995) Microalbuminuria reflects a generalized transvascular albumin leakiness in clinically healthy subjects. Clin Sci Lond Engl 1979 88:629-633

69. Clausen P, Jensen JS, Jensen G et al (2001) Elevated urinary albumin excretion is associated with impaired arterial dilatory capacity in clinically healthy subjects. Circulation 103:1869-1874

70. De Nicola L, Provenzano M, Chiodini P et al (2017) Epidemiology of low-proteinuric chronic kidney disease in renal clinics. PLoS One 12:e0172241. https://doi.org/10.1371/journ al.pone. 0172241

71. Roscioni SS, Heerspink HJL, de Zeeuw D (2014) The effect of RAAS blockade on the progression of diabetic nephropathy. Nat Rev Nephrol 10:77-87. https://doi.org/10.1038/nrneph.2013.251

72. Schmidt M, Mansfield KE, Bhaskaran K et al (2017) Serum creatinine elevation after renin-angiotensin system blockade and long term cardiorenal risks: cohort study. BMJ 356:j791

73. Bellizzi V, Conte G, Borrelli S et al (2017) Controversial issues in CKD clinical practice: position statement of the CKD-treatment working group of the Italian Society of Nephrology. J Nephrol 30:159-170. https://doi.org/10.1007/s40620-016-0338-x

74. De Nicola L, Zamboli P, Bellizzi V et al (2011) Antiproteinuric response to add-on aliskiren in proteinuric patients treated with dual blockade of the renin-angiotensin system: a 12-month prospective uncontrolled study. Am J Kidney Dis 57:961-963. https:// doi.org/10.1053/j.ajkd.2011.02.384 
75. Fried LF, Emanuele N, Zhang JH et al (2013) Combined angiotensin inhibition for the treatment of diabetic nephropathy. N Engl J Med 369:1892-1903. https://doi.org/10.1056/NEJMo a1303154

76. Palmer SC, Mavridis D, Navarese E et al (2015) Comparative efficacy and safety of blood pressure-lowering agents in adults with diabetes and kidney disease: a network meta-analysis. Lancet Lond Engl 385:2047-2056. https://doi.org/10.1016/S0140 $-6736(14) 62459-4$

77. Tylicki L, Rutkowski P, Renke M et al (2008) Triple pharmacological blockade of the renin-angiotensin-aldosterone system in nondiabetic CKD: an open-label crossover randomized controlled trial. Am J Kidney Dis 52:486-493. https://doi. org/10.1053/j.ajkd.2008.02.297

78. Yavin Y, Mansfield TA, Ptaszynska A et al (2016) Effect of the SGLT2 inhibitor dapagliflozin on potassium levels in patients with type 2 diabetes mellitus: a pooled analysis. Diabetes Ther Res Treat Educ Diabetes Relat Disord 7:125-137. https://doi. org/10.1007/s13300-015-0150-y

79. Kohan DE, Fioretto P, Johnsson K et al (2016) The effect of dapagliflozin on renal function in patients with type 2 diabetes. J Nephrol 29:391-400. https://doi.org/10.1007/s40620-016-0261-1

80. Paoletti E, Cassottana P, Bellino D et al (2002) Left ventricular geometry and adverse cardiovascular events in chronic hemodialysis patients on prolonged therapy with ACE inhibitors. Am J Kidney Dis 40:728-736. https://doi.org/10.1053/ajkd.2002.35680

81. Paoletti E, Bellino D, Signori A et al (2016) Regression of asymptomatic cardiomyopathy and clinical outcome of renal transplant recipients: a long-term prospective cohort study. Nephrol Dial Transplant 31:1168-1174. https://doi.org/10.1093/ ndt/gfv354

82. Epstein M, Reaven NL, Funk SE et al (2015) Evaluation of the treatment gap between clinical guidelines and the utilization of renin-angiotensin-aldosterone system inhibitors. Am J Manag Care 21:S212-220

83. Ponikowski P, Voors AA, Anker SD et al (2016) 2016 ESC Guidelines for the diagnosis and treatment of acute and chronic heart failure: the Task Force for the diagnosis and treatment of acute and chronic heart failure of the European Society of Cardiology (ESC)Developed with the special contribution of the Heart Failure Association (HFA) of the ESC. Eur Heart J 37:2129-2200. https://doi.org/10.1093/eurheartj/ehw128

84. Navaneethan SD, Nigwekar SU, Sehgal AR, Strippoli GFM (2009) Aldosterone antagonists for preventing the progression of chronic kidney disease: a systematic review and meta-analysis. Clin J Am Soc Nephrol 4:542-551. https://doi.org/10.2215/ CJN.04750908

85. Goraya N, Simoni J, Jo C-H, Wesson DE (2013) A comparison of treating metabolic acidosis in CKD stage 4 hypertensive kidney disease with fruits and vegetables or sodium bicarbonate. Clin J Am Soc Nephrol 8:371-381. https://doi.org/10.2215/CJN.02430 312

86. Lepage L, Dufour A-C, Doiron J et al (2015) Randomized clinical trial of sodium polystyrene sulfonate for the treatment of mild hyperkalemia in CKD. Clin J Am Soc Nephrol 10:2136-2142. https://doi.org/10.2215/CJN.03640415

87. Nguyen T, Ondrik D, Zhufyak O et al (2015) Hyperkalemia and potential pitfalls of sodium polystyrene sulfonate. JAAPA 28:41-45. https://doi.org/10.1097/01.JAA.0000458856.92020.1e

88. Sterns RH, Rojas M, Bernstein P, Chennupati S (2010) Ionexchange resins for the treatment of hyperkalemia: are they safe and effective? J Am Soc Nephrol 21:733-735. https://doi. org/10.1681/ASN.2010010079

89. Bakris GL, Weir MR (2000) Angiotensin-converting enzyme inhibitor-associated elevations in serum creatinine: is this a cause for concern? Arch Intern Med 160:685-693
90. Wolf G, Ritz E (2005) Combination therapy with ACE inhibitors and angiotensin II receptor blockers to halt progression of chronic renal disease: pathophysiology and indications. Kidney Int 67:799-812. https://doi.org/10.1111/j.1523-1755.2005.00145 .x

91. Leonberg-Yoo AK, Tighiouart H, Levey AS et al (2017) Urine potassium excretion, kidney failure, and mortality in CKD. Am J Kidney Dis 69:341-349. https://doi.org/10.1053/j. ajkd.2016.03.431

92. Elbehary S, Szerlip HM, McCullough PA (2017) Potassium excretion and outcomes in CKD: is k intake ok? Am J Kidney Dis 69:325-327. https://doi.org/10.1053/j.ajkd.2016.11.009

93. Wu X, Zhang W, Ren H et al (2014) Diuretics associated acute kidney injury: clinical and pathological analysis. Ren Fail 36:1051-1055. https://doi.org/10.3109/0886022X.2014.917560

94. Agarwal R, Sinha AD, Pappas MK, Ammous F (2014) Chlorthalidone for poorly controlled hypertension in chronic kidney disease: an interventional pilot study. Am J Nephrol 39:171-182. https://doi.org/10.1159/000358603

95. Kessler C, Ng J, Valdez K et al (2011) The use of sodium polystyrene sulfonate in the inpatient management of hyperkalemia. J Hosp Med 6:136-140. https://doi.org/10.1002/jhm.834

96. DailyMed-SODIUM POLYSTYRENE SULFONATE-sodium polystyrene sulfonate suspension. https://dailymed.nlm.nih.gov/ dailymed/drugInfo.cfm?setid=12d48dcf-07bd-4b06-bd6c-7543f 1be8357. Accessed 24 Jan 2018

97. Yu M-Y, Yeo JH, Park J-S et al (2017) Long-term efficacy of oral calcium polystyrene sulfonate for hyperkalemia in CKD patients. PLoS One 12:e0173542. https://doi.org/10.1371/journ al.pone. 0173542

98. Buysse JM, Huang I-Z, Pitt B (2012) PEARL-HF: prevention of hyperkalemia in patients with heart failure using a novel polymeric potassium binder, RLY5016. Future Cardiol 8:17-28. https ://doi.org/10.2217/fca.11.71

99. Weir MR, Bakris GL, Gross C et al (2016) Treatment with patiromer decreases aldosterone in patients with chronic kidney disease and hyperkalemia on renin-angiotensin system inhibitors. Kidney Int 90:696-704. https://doi.org/10.1016/j. kint.2016.04.019

100. He J, Mills KT, Appel LJ et al (2016) Urinary sodium and potassium excretion and CKD progression. J Am Soc Nephrol 27:1202-1212. https://doi.org/10.1681/ASN.2015010022

101. Bushinsky DA, Williams GH, Pitt B et al (2015) Patiromer induces rapid and sustained potassium lowering in patients with chronic kidney disease and hyperkalemia. Kidney Int 88:14271433. https://doi.org/10.1038/ki.2015.270

102. York KENPharmD, BCPSAssistant ProfessorSt John's UniversityCollege of Pharmacy and Health SciencesDepartment of Clinical Health ProfessionsQueens, New York Chung-Shien Lee, PharmD, BCPS, BCOPAssistant ProfessorSt John's UniversityCollege of Pharmacy and Health SciencesDepartment of Clinical Health ProfessionsQueens, New Updated Treatment Options in the Management of Hyperkalemia. https://www.uspha rmacist.com/article/updated-treatment-options-in-the-manag ement-of-hyperkalemia. Accessed 25 Jan 2018

103. Packham DK, Rasmussen HS, Lavin PT et al (2015) Sodium zirconium cyclosilicate in hyperkalemia. N Engl J Med 372:222231. https://doi.org/10.1056/NEJMoa1411487

104. Administration AGD of HTG (2018) AusPAR: sodium zirconium cyclosilicate hydrate. In: Ther. Goods Adm. TGA. https://www. tga.gov.au/auspar/auspar-sodium-zirconium-cyclosilicate-hydra te. Accessed 15 Feb 2018 